\title{
Standard Strain and Strain Rate by Two-Dimensional Speckle Tracking in Agoutis (Dasyprocta prymnolopha) Anesthetized with Ketamine and Xylazine
}

\author{
Renan Paraguassu de Sá Rodrigues', Gerson Tavares Pessoa ${ }^{2}$, Laecio da Silva Moura', \\ Andrezza Braga Soares da Silva', Francisco das Chagas Araújo Sousa ${ }^{3}$, Igor Carvalho Santos ${ }^{1}$, \\ Jefferson Rodrigues Araújo' ${ }^{1}$, Jacyara de Jesus Rosa Pereira Alves ${ }^{4}$, \\ Kássio Vieira Macedo ${ }^{5}$ \& Flávio Ribeiro Alves ${ }^{6}$
}

\begin{abstract}
Background: The agouti (Dasyprocta prymnolopha, Wagler, 1831) is a wild rodent widely found throughout America which has stood out as a good animal model for scientific investigations. The aim of this study was to study the cardiovascular function of chemically contained agoutis, by performing echocardiographic examinations and measuring Strain and Strain Rate by Speckle Tracking to obtain reference values for the species and verify the applicability of these animals as models for the study of cardiovascular changes in humans.

Materials, Methods \& Results: It was selected 16 animals, sedated by the combination of ketamine hydrochloride and xylazine and submitted to transthoracic echocardiography. To obtain the standard measurements, B, M and Doppler mode images were taken. The analysis of the radial and longitudinal myocardial deformation of the left ventricle was carried out. The right parasternal window was used for access to the short cardiac axis and the left for access to the long axis. Six radial profiles of strain (ST) and Strain rate (SR) values were obtained, corresponding to the mean of the values for each segment. A total of 18 myocardial segments were analyzed for each specimen and the mean values were used to compose the statistical analysis. The comparison of the means between the genders did not show statistical difference, being the other statistical treatments based on the total sample of 16 animals. The variables that showed statistically significant correlation coefficients in relation to weight were: LA, LA/AO, HR, AVmax, E' wave, E/IVRT $(P>0.05)$. HR showed a positive correlation with IVSd $(r=0.51)$, EPSS $(r=0.55)$ and E' wave $(r=0.68)$; negative with IVRT $(r=-0.41)$, A wave $(\mathrm{r}=-0.54), \mathrm{AV} \max (\mathrm{r}=-0.53)$ and Pmax $(\mathrm{r}=-0.65)$.

Discussion: Although presumptively normal echocardiographic values were reported for not anesthetized agoutis, this was the first study to show the measurement of these variables for chemically contained agoutis, in addition to the use of Strain and strain rate by speckle tracking in the assessment of cardiac function. The sudden exposure of an external stimulus (environmental or physical) to which the body is not adapted can trigger an acute stress, and its effects may interfere significantly in the measurement of hemodynamic variables, justifying the need for chemical containment. The values found for the thickness of agoutis cardiac walls and chambers obtained in M mode, both in systole and in diastole, when compared with mammals of different size, confirm the positive linear correlation between body weight and cardiac dimensions for the various evaluated parameters. The velocity obtained by the Strain radial for the apical systolic peak was slightly lower than that obtained for the basal systolic peak, while the opposite was observed for the circumferential Strain, which showed apical peak greater than the basal peak, also to the found for human beings. The values obtained for circumferential, radial and longitudinal strain for agoutis were within the ranges of normality observed in healthy domestic animals and humans.
\end{abstract}

Keywords: animal models, cardiology, rodents, wild animals.

${ }^{1}$ Animal Science Post-Graduate Program \& ${ }^{2}$ Medical Residence in Veterinary Image Diagnosis, Federal University of Piauí (UFPI), Teresina, PI, Brazil. ${ }^{3}$ State University of Piauí, Faculty of Medical Science (UESPI), Teresina. ${ }^{4}$ Coloproctology and Colorectal Surgery Service of the University Hospital, UFPI, Teresina. ${ }^{5}$ Health Science Post-Graduate, UFPI, Teresina. ${ }^{6}$ Department of Veterinary Morphophysiology, Agrarian Science Center, UFPI, Teresina. CORRESPONDENCE: F.R. Alves [flavioribeiro@ufpi.edu.br - Tel.: +55 (86) 3215-5757]. Department of Veterinary Morphophysiology, Agrarian Science Center, UFPI. CEP 64049-550 Teresina, PI, Brazil. 


\section{INTRODUCTION}

The agouti (Dasyprocta prymnolopha, Wagler, 1831 ) is a wild rodent found in almost all of America that has demonstrated good results as an experimental model in cardiovascular studies [15,31].

Currently, human heart disease is modeled mainly in small rodents, such as rats and mice [26]. However, the echocardiographic study of these animals has limitations on cardiac guidance and the need for high frequency transducers, often inaccessible [5]. In turn, large animals such as swine and sheep have been tested instead of some rodents, especially due to their greater weight and size [29]. However, these require large areas for breeding, in addition to expensive and laborious management, limiting the researches financially.

In this context, the agouti has been highlighted by the fact that it combines in a single species the cardiovascular morphological similarity with humans, management of simplified breeding, docility, low breeding costs and good reproductive indexes $[15,42]$. In addition, larger than most rodents used as animal models, they suffer less influence from HR, especially on chemical containment, allowing reliable measurements on echocardiographic examination [15].

The objective of this study was to study the cardiovascular function of the chemically contained agoutis in B, M and Doppler echocardiographic tests and to measure the Strain and Strain Rate by Speckle Tracking to obtain reference values for the species and verify the applicability of these animals as models for the study of cardiovascular changes in humans.

\section{MATERIALS AND METHODS}

\section{Animals}

For this study, 16 black-rumped agoutis (eight males and eight females) were used from the Center for Studies and Preservation of Wild Animals (NEPAS), Federal University of Piauí (UFPI), Teresina, Piauí, Brazil. The protocols used in this study were approved by Committee on Ethics in Animal Experimentation - CEAA / UFPI (No 0117 / 2015) and authorized by the Ministry of the Environment, through the System of Authorization and Information of Biodiversity SISBIO of the Brazilian Institute of the Environment and Natural Renewable Resources - IBAMA (No $26101-1)$.
Exclusion criteria

The animals were submitted to clinical, hematological and biochemical examination. Auscultation of lung fields and cardiac sounds was performed. There was follow-up by electrocardiographic examination and screening echocardiogram. Animals that had valvular insufficiencies identified on auscultation, confirmed on the echocardiogram, as well as rhythm disturbances identified on the electrocardiogram were excluded from the experiment [47].

Anesthetic protocol

The agoutis were pre-prepared with a $12-\mathrm{h}$ solid fasting and $4 \mathrm{~h}$ water fasting. Later they were captured using restraint nets and physically contained with leather gloves for the application of anesthetic drugs.

Sedation occurred by intramuscular application of the combination of $15 \mathrm{mg} / \mathrm{kg}$ ketamine hydrochloride $5 \%$ and $1.0 \mathrm{mg} / \mathrm{kg}$ xylazine. Approximately 5 to 10 min after the application, the anesthetic action was observed, where the procedures to perform the echocardiographic exams were started. The protocols promoted an average anesthetic time of 30 to $40 \mathrm{~min}$ in all the animals, and there was no need to reapply the drugs during the exams. During the tests until complete recovery, the vital parameters of the animals such as heart rate $(\mathrm{HR})$, respiratory rate $(\mathrm{RR})$ and rectal temperature were monitored.

\section{Standard echocardiographic assessment}

The animals were positioned in the left and right lateral decubitus position, with the clipped hair from the thoracic surface and the chest evaluated after the application of conductive gel for echocardiography ${ }^{1}$. Transthoracic echocardiographic examination was performed using a portable ultrasound equipment ${ }^{2}$, coupled to a multifrequency probe $(4.0$ to $8.0 \mathrm{MHz})^{2}$. B, M and Doppler mode images were acquired to obtain the standard measurements by previously established protocols for humans and small animals $[7,44]$. All the exams were performed with simultaneous electrocardiographic tracing in DII.

Three representative cardiac cycles were analyzed and the mean was calculated for each variable. Measurements included the diameter of the root of the aorta 2D (Ao), the left atrium (LA) of the short axis (right parasternal) and LA/AO ratio. 
In the right parasternal window (level of the chordae tendineae) images were obtained in systole and diastole to calculate the thickness of the interventricular septum (IVS) and free wall (LVFW), in addition to the internal dimension of the left ventricle (LVID). Using the same window, measurements of the distance between the $\mathrm{E}$ point of the anterior leaflet of the mitral valve and the interventricular septum (EPSS) were obtained from the short axis using M-mode images. In apical section 4 chambers were measured the E' and A' waves of the left ventricular tissue Doppler (insertion point of the septal leaflet of the mitral valve) [Figures $1 \& 2$ ].

Measurements of spectral Doppler included transmitral flow (E wave and A wave - apical 4 chambers), maximal aortic blood flow velocity (AV) and isovolumetric relaxation time (IVRT), measured from aortic valve closure to the opening of the mitral valve, from an apical 5-chamber cut, in window to left sterna, using the pulsed wave Doppler (PW). The E/A and E/IVRT ratios were derived automatically from the previously calculated measures for $\mathrm{E}$ and A waves of the mitral valve and IVTR. Pulmonary blood flow velocities (Pmax) were recorded with the PW Doppler from the short axis (pulmonary plane) in the right parasternal window. The sample volume was positioned immediately after the pulmonary valve (Figure 3).

The heart rate (HR) was obtained for each cycle during automatic acquisition by the software in the machine, measuring the distance of the pulmonary artery pulsed Doppler flow spectra. The mean of all heartbeats recorded during the examination of each agouti was defined as HR. The maximum and minimum HR values were also documented. The presence of valve insufficiency was investigated by color Doppler on each valve individually. The $2 \mathrm{D}$ sector size has been minimized to improve image quality. The highest pulse repetition frequency (PRF) was used to avoid signs of aliasing in normal flows.

\section{Strain by speckle tracking measurements}

To obtain the values of cardiac deformation, an Affinity $50^{3}$ ultrasound device was used, coupled to a multifrequencial phase array probe (5-8 MHz), and ACMQA.I - Automated Cardiac Motion Quantification software, which performed the analysis of the radial and longitudinal myocardial deformation of the left ventricle. After the conventional echocardiographic examination, the right and left parasternal window for video acquisition was accessed at a frame reproduction rate of 70 to $110 \mathrm{frames} / \mathrm{s}$, as described in dogs [11] and humans [46] (Figure 4).

For each animal, three consecutive cardiac cycles were recorded using a single circuit and the information was digitally stored on a hard disk for offline analysis on a workstation.

The right parasternal window was used to access the short cardiac axis and the left parasternal for long axis access (apical 4 chambers, 2 chambers and 5 chambers) - the endocardial edges of the left ventricle were traced manually at the end of diastole. In each cut plane, a region of interest was automatically delineated from the endocardial border. Then, the software algorithm automatically divided the cut plane of the left ventricle short and long axes into 6 segments (involving the interventricular septum and the free wall) for the tracing of points in the myocardium (Speckles).

The speckles search was performed frameby-frame, generating a score that represents the reliability of the tracking (ranging from poor to excellent) based on matching blocks of the algorithm. Six radial profiles of ST (strain - strain rate) and SR (Strain rate - strain velocity) values were obtained, corresponding to the mean values for each segment. These values of radial ST and radial maxima at the radial systolic peak were referenced by means of six curves and the mean values were calculated in order to characterize the overall ST and SR during the left ventricle systolic peak. The myocardial synchronism was accessed by the difference between the initial and final systolic peak moment. A total of 18 myocardial segments were analyzed for each specimen and the mean values were used to compose the statistical analysis (figure 5).

\section{Statistical analysis}

The Graphpad Prism 7 software was used to analyze the data and to run the non-parametric test wilcoxon-mann-whitney (U of Mann-Whitney) to verify the existence of differences between the variables addressed with regard to the sex of the animals. The Spearman rank correlation coefficient was used to assess dependence. In the test, 0.05 was considered as a level of significance. 

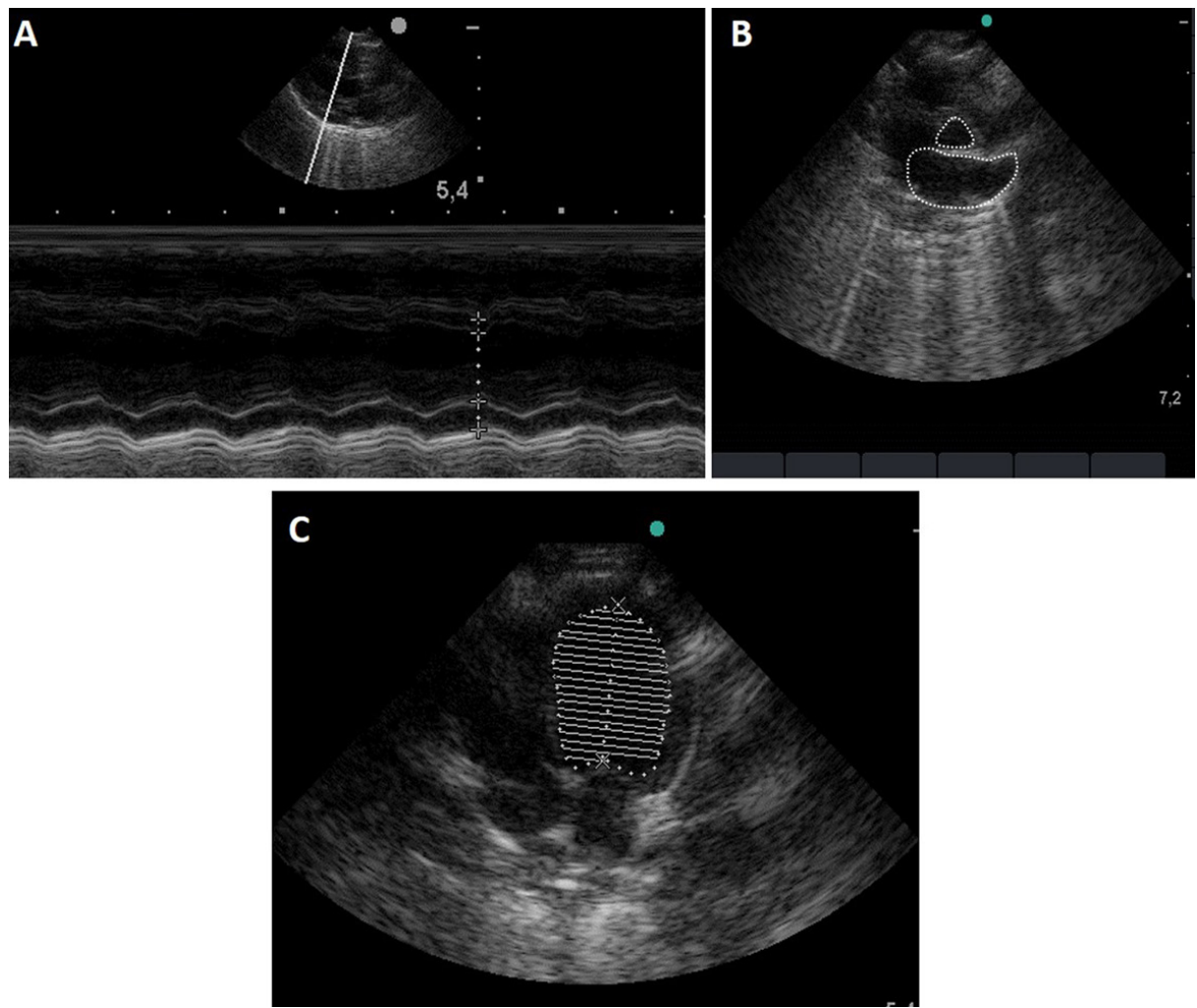

Figure 1. M-mode and two-dimensional (2D) echocardiographic images obtained from anesthetized agoutis (Dasyprocta prymnolopha). A- M-mode was used for the measurements of the interventricular septal wall, left ventricular wall, and left ventricular internal dimensions. B- Two-dimensional right short axis view at the base of the heart used to measure the LA/AO ratio. C- Left apical 4-chamber view for measurement of the echocardiographic end-diastolic and end-systolic left ventricular volumes using Simpson's method of discs.

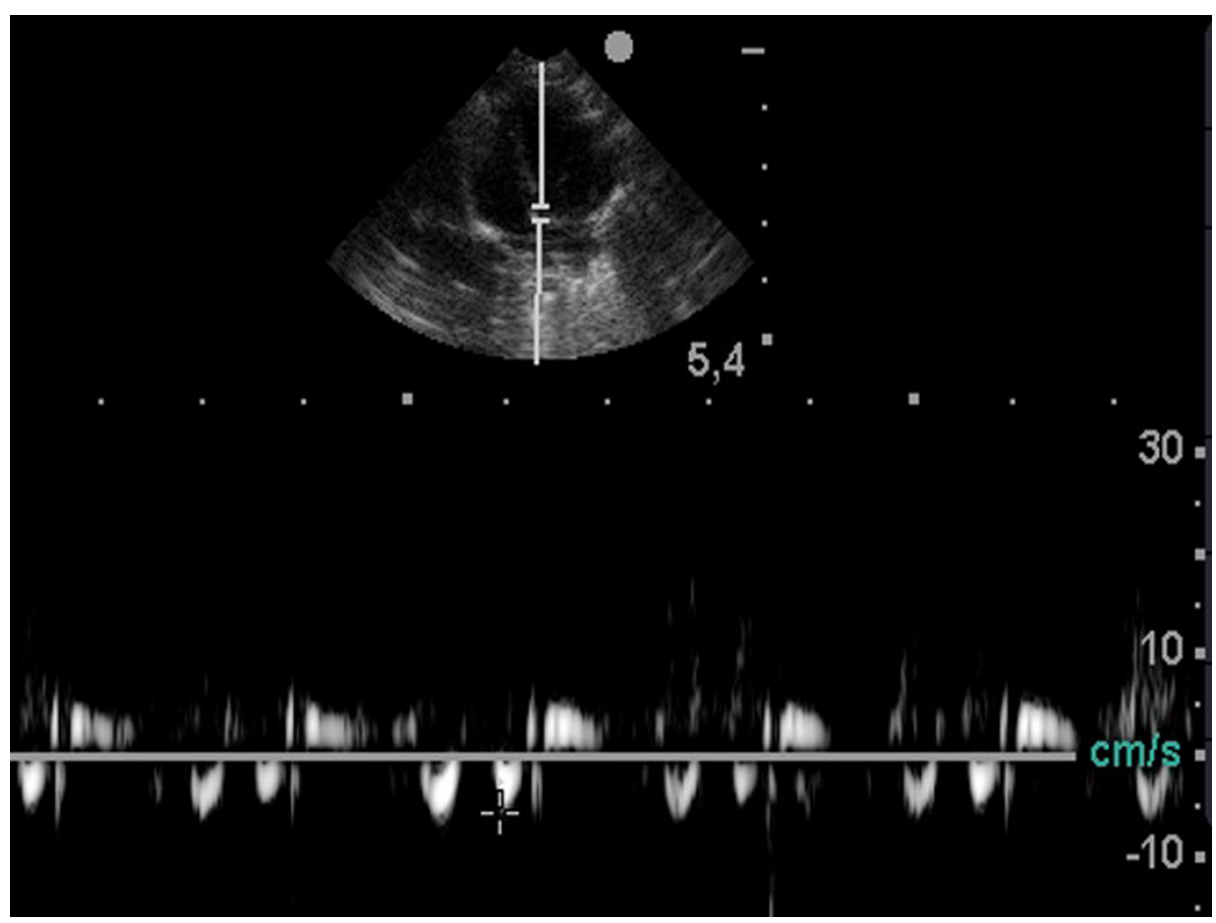

Figure 2. Pulsed-wave tissue Doppler imaging (PWTDI) mode images obtained from anesthetized agoutis (Dasyprocta prymnolopha). PWTDI from the apical 4-chamber view sampling the septal mitral annulus. 

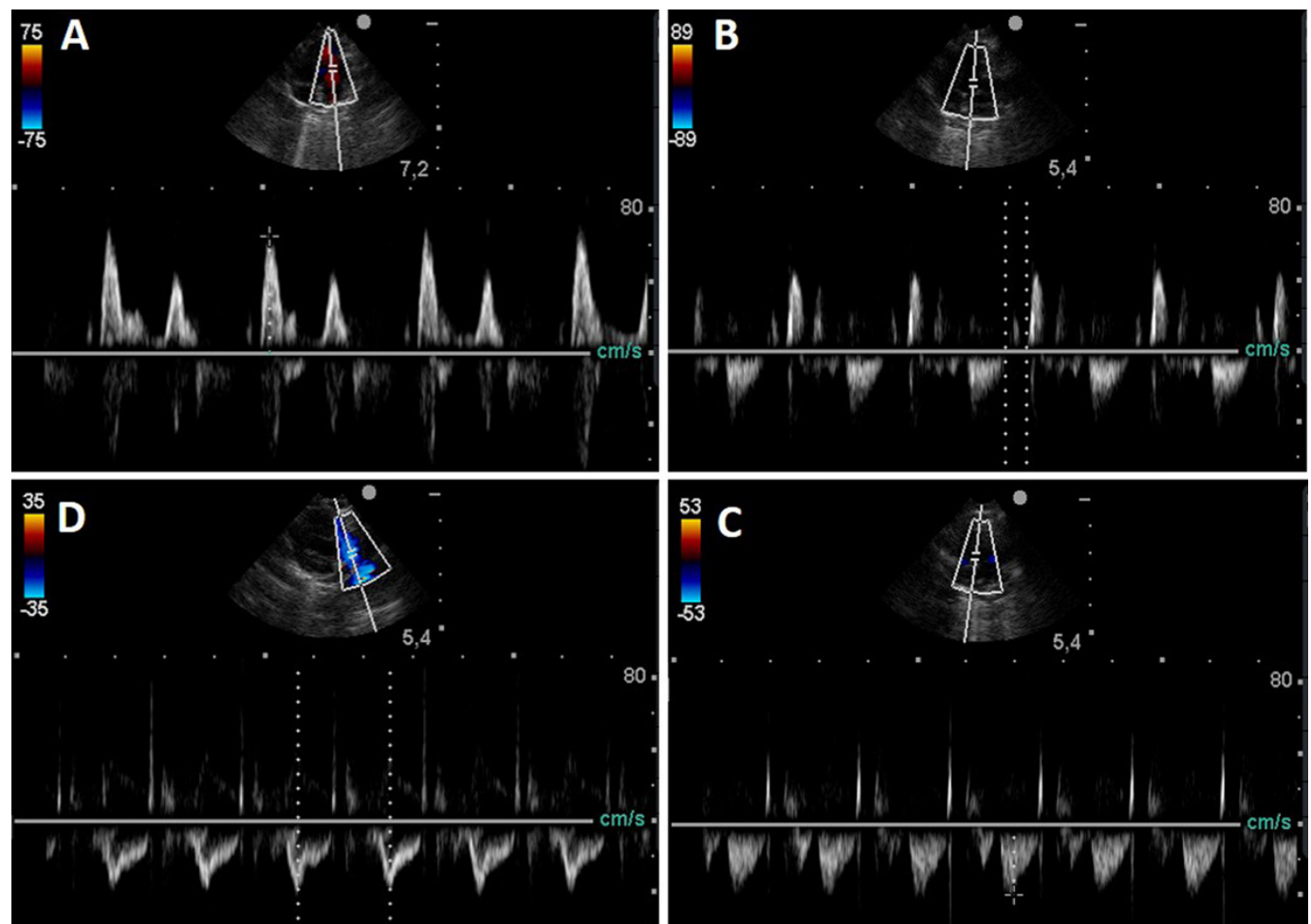

Figure 3. Doppler echocardiographic images obtained from anesthetized agoutis (Dasyprocta prymnolopha). A- Pulsed-wave Doppler inflow assessment of the mitral valve showing the early diastolic mitral inflow (E) and late diastolic mitral inflow. B- Doppler measurements, including the peak aortic blood flow velocity and the mitral inflow, were used to measure the isovolumic relaxation time (IVRT) obtained from the left apical 5-chamber view. Pulsed Doppler assessment of the pulmonary

(C) and aortic flow velocity curves (D).

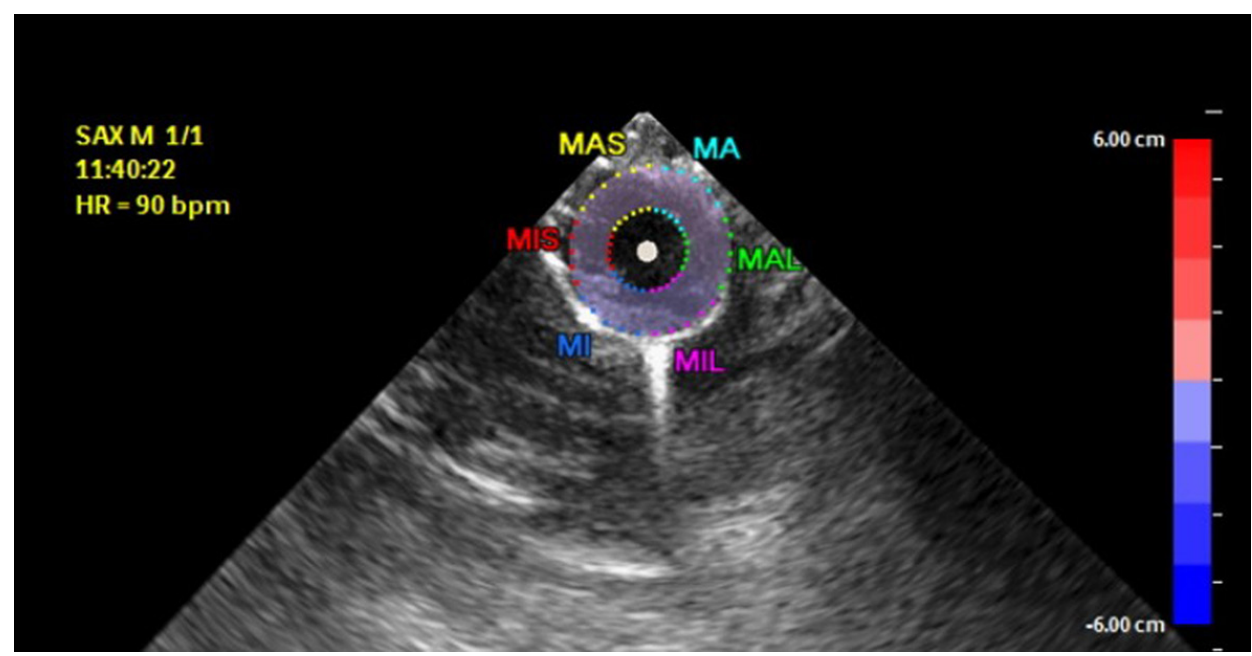

Figure 4. Speckle tracking echocardiography at the level of the apex in a agouti (Dasyprocta prymnolopha). The software algorithm automatically separates the LV short-axis into 6 myocardial segments to include the interventricular septum and the LV free wall. The tracking approval of each individual myocardial segment is displayed on the screen. 

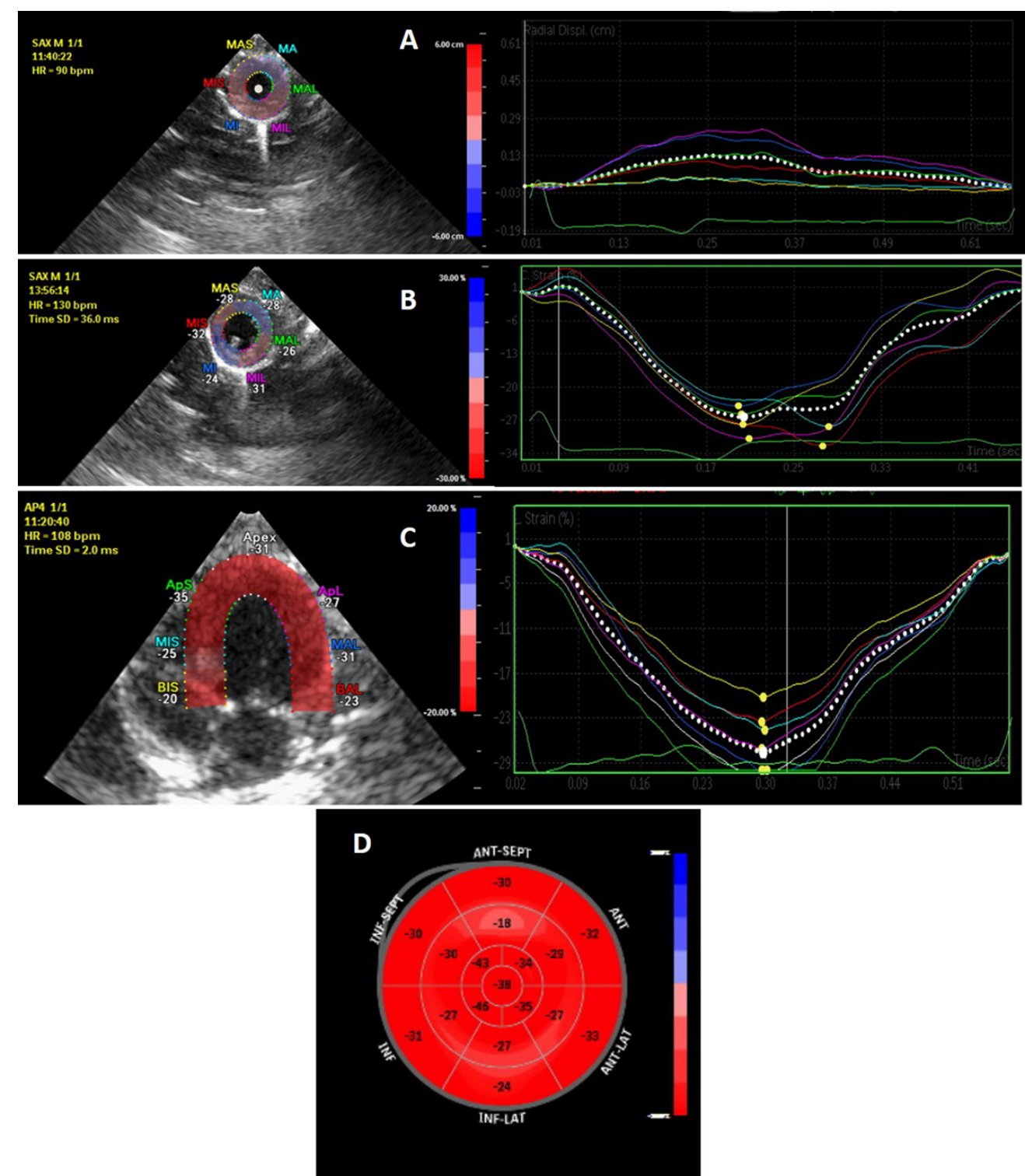

Figure 5. Echocardiographic examination evidencing radial (A), circumferential (B) and longitudinal strain (C) of agouti (Dasyprocta prymnolopha). Note that all segments of the myocardium contract adequately and strain values are within the reference values, including for humans.

\section{RESULTS}

Table 1 shows the echocardiographic parameters of the group of animals studied. The comparison of the means between the genders did not show statistical difference $(P>0.05, P=0.659)$. Thus, the remaining statistical treatments were based on the total sample of 16 animals. The variation reference intervals were determined by the calculated $95 \%$ tolerance interval, designed to cover $99 \%$ of all future events. The variables that showed statistically significant correlation coefficients in relation to weight were: LA, LA/AO,
HR, AVmax, E' wave, E/IVRT $(P>0.05)$ [Table 1]. The other variables that showed correlations between them are described below: HR showed a positive correlation with IVSd $(r=0.51)$, EPSS $(r=0.55)$ and E' wave $(r=0.68)$; negative with IVRT $(r=-0.41)$. The LA variable showed a positive correlation with $\mathrm{AO}(\mathrm{r}$ $=0.70)$ and IVRT $(r=0.47)$. FS presented a positive correlation with E/IVRT $(r=0.67)$ and $E$ wave $(r=$ 0.38 ). Table 2 shows the values found for the advanced echocardiographic measurements derived from the strain by speckle tracking. 
Table 1. Normal values for bidimensional echocardiographic variables in B, M and Doppler modes as observed in healthy agoutis that were anesthetized with ketamine and xylazine.

\begin{tabular}{|c|c|c|c|c|c|}
\hline Variable & Mean & SD & Reference range & $\mathrm{r}$ & $P$ value \\
\hline $\mathrm{BW}(\mathrm{Kg})$ & 2.86 & 0.26 & $2.5-3.25$ & - & - \\
\hline $\mathrm{AO}(\mathrm{cm})$ & 0.63 & 0.11 & $0.54-0.87$ & -0.227 & 0.131 \\
\hline $\mathrm{LA}(\mathrm{cm})$ & 1.01 & 0.15 & $0.69-1.19$ & $0.469^{\mathrm{a}}$ & 0.362 \\
\hline $\mathrm{LA} / \mathrm{AO}$ & 1.64 & 0.35 & $1.17-2.13$ & $0.545^{\mathrm{a}}$ & 0.474 \\
\hline IVSd (cm) & 0.35 & 0.10 & $0.26-0.60$ & -0.111 & 0.368 \\
\hline IVSs (cm) & 0.39 & 0.09 & $0.2-0.58$ & 0.088 & 0.342 \\
\hline LVFWd (cm) & 0.30 & 0.09 & $0.22-0.4$ & -0.101 & 0.636 \\
\hline LVFWs (cm) & 0.45 & 0.08 & $0.34-0.63$ & 0.190 & 0.670 \\
\hline LVIDd (cm) & 1.49 & 0.21 & $1.14-1.83$ & 0.07 & 0.981 \\
\hline LVIDs (cm) & 1.06 & 0.17 & $0.86-1.37$ & 0.248 & 0.355 \\
\hline $\mathrm{EF}(\%)$ & 60.1 & 10.56 & $43-78$ & -0.136 & 0.970 \\
\hline FS $(\%)$ & 29.11 & 7.3 & $20-43$ & 0.209 & 0.486 \\
\hline HR (bmp) & 146.4 & 27.8 & 103-197 & $-0.669^{a}$ & 0.929 \\
\hline EPSS $(\mathrm{cm})$ & 0.26 & 0.07 & $0.17-0.40$ & -0.272 & 0.379 \\
\hline E wave $(\mathrm{cm} / \mathrm{s})$ & 62.55 & 8.48 & $45-75.70$ & 0.289 & 0.378 \\
\hline A wave $(\mathrm{cm} / \mathrm{s})$ & 41.83 & 9.0 & $27.9-52.9$ & 0.166 & 0.751 \\
\hline $\mathrm{AV} \max (\mathrm{cm} / \mathrm{s})$ & 66.18 & 16.69 & $40-85.2$ & $0.380^{\mathrm{a}}$ & 0.344 \\
\hline $\operatorname{Pmax}(\mathrm{cm} / \mathrm{s})$ & 55.98 & 11.74 & $40.4-75.7$ & 0.320 & 0.789 \\
\hline IVTR (ms) & 71.47 & 11.96 & $55-90$ & -0.294 & 0.654 \\
\hline E' wave $(\mathrm{cm} / \mathrm{s})$ & 7.02 & 1.43 & $3.97-9.47$ & $-0.481^{a}$ & 0.191 \\
\hline $\mathrm{A}^{\prime}$ wave $(\mathrm{cm} / \mathrm{s})$ & 4.69 & 1.16 & $2.8-6.78$ & -0.144 & 0.895 \\
\hline $\mathrm{E} / \mathrm{A}$ & 1.58 & 0.46 & $1.05-2.18$ & 0.018 & 0.134 \\
\hline E/IVRT & 0.99 & 0.38 & $0.5-1.96$ & $0.438^{\mathrm{a}}$ & 0.127 \\
\hline
\end{tabular}

Variables that correlated significantly with weigh.

Table 2. Left Ventricle peak systolic strain and twist measurements obtained by speckle tracking echocardiography (STE), measurement error and coefficient of variation in anesthetized Agoutis.

\begin{tabular}{cccc}
\hline Variable & Measurements & SD & Reference interval \\
\hline Peak apical systolic radial strain (\%) & 42.16 & 4.31 & 39.85 to 47.94 \\
Peak apical circumferential strain (\%) & -21.36 & 3.74 & -27.1 to -17.63 \\
Peak basal systolic radial strain (\%) & 43.12 & 4.75 & 36.7 to 48.87 \\
Peak basal circumferential strain (\%) & -16.71 & 3.81 & -23.15 to -9.20 \\
Peak longitudinal strain (\%) & -27.49 & 4.53 & -34.9 to -16.51 \\
Left ventricle torsion (degrees) & 3.03 & 0.41 & 2.33 to 3.57 \\
Global Strain (\%) & -21.87 & 1.17 & -24.1 to -19.87 \\
Basal Torsion (\%) & -4.13 & 1.86 & -6.67 to -1.45 \\
Apical Torsion (\%) & -12.05 & 2.37 & -14.17 to -6.95 \\
\hline
\end{tabular}




\section{DISCUSSION}

Several studies have demonstrated normal echocardiographic parameters for domestic animals such as dogs, cats, horses, sheep [7,9,27], as well as wild rodents such as prairie dogs (Cynomys ludovicianus) [20], guinea pigs (Cavia porcellus) [10] and New Zealand rabbits [41]. However, although presumptive normal echocardiographic values were reported for non-anesthetized agoutis [15], this is the first study to show the measurement of these variables for chemically contained agoutis, in addition to the use of strain and strain rate by speckle tracking in the evaluation of cardiac function.

It is known that physical restraint is one of the main stressors, and can easily lead to death [4]. The sudden exposure of a given stimulus to which the body is not adapted can trigger an acute stress, characterized by an increase in heart and respiratory rate, and these effects may significantly interfere in the measurement of hemodynamic variables [32], justifying the need for chemical containment.

The HR in this study was like the findings for agoutis anesthetized by the same protocol [42] and for pacas (Cuniculus paca), similar sized rodents, also chemically contained [48]. However, it was lower when compared to values obtained for non-anesthetized agoutis [14,15], New Zealand rabbits [41] and guinea pigs [8], smaller rodents. HR is inversely proportional to the size of the animal, being higher in smaller species [39]. The difference between the values found for HR of anesthetized and non-anesthetized agoutis is mainly due to the elimination of the stress factor, achieved by sedation [4]. The antagonism to the cardio depressant effects of ketamine, promoted by xylazine, contributed to the maintenance of normal HR in the animals of this experiment [18].

The comparison of the mean of the studied variables, between males and females, did not show statistical differences $(P>0.05, P=0.659)$, like that found for this same species under physical restraint and for ferrets [15,49]. Adult individuals of the genus Dasyprocta have small anatomical variation, resulting in a very similar cardiovascular physiology between males and females, directly reflecting the variables measured in the present study [19].

The variables LA, LA/AO, HR, AVmax, E' wave, E/IVRT $(P>0.05)$ demonstrated a statistically significant correlation coefficient in relation to body weight. Similar correlations were described between body weight and DVEd, LA, AO and SIV in dogs of various breeds [34] and SIV, PLVE [37] and LA in cats [2]. Likewise, in monkeys, similar correlations were observed between the variables AO, LVFW, LA/AO, LVIDd and LVIDs and body weight for several species [43].

The values found for the thickness of agoutis heart walls and chambers when compared to mammals of different sizes, including wild rodents [20], unanesthetized agoutis [15], New Zealand rabbits [41], hedgehogs (Atelerix albiventris) [6] and ferrets (Mustela putorius furo) [49], confirm the positive linear correlation between body weight and heart dimensions for the various parameters evaluated.

The EPSS presented values lower than those found for conventional pigs, minipigs [27] and New Zealand rabbits [41] and higher than the findings for hedgehogs [6] and non-anesthetized agoutis [15]. Despite the differences, all are consistent with the literature, since for most species, including humans, the normal EPSS value is less than $1.0 \mathrm{~cm}$ [3]. These values do not change with the size of the ventricular chamber, except in cases where the function is diminished, as in valvular diseases, and can be used as a qualitative method to evaluate the LV systolic function [24,25]. Magnetic resonance studies have confirmed the applicability of this value as a quantitative predictor of left ventricular function in humans [16].

The mean value found for left ventricular ejection fraction (EF) values was similar to standard values for minipigs [27] and lower when compared to New Zealand rabbits [41], guinea pigs and non-anesthetized agoutis [10]. This difference can be justified by the depressant effects of ketamine, which promotes early ventricular depolarization, interfering with blood pressure, heart rate and cardiac output [28,30]. In medicine, EF values can be influenced by several variables such as contractility, heart rate, preload and afterload [17]. Corroborating these findings, a 7\% reduction in EF was demonstrated in a group of rabbits anesthetized with ketamine associated to midazolam compared to rabbits sedated with midazolam alone [45].

The shortening fraction (FS) correlated positively with the E/A ratio $(r=0.61)$, suggesting that in these animals this variable may reflect moderately the pressure changes in the left atrium. Although within normal limits, compared to animal models like minipigs [27], FS showed values lower than those seen 
in humans [3], probably due to the cardio depressor effect provided by ketamine, given the fact that all presented animal models were studied under sedation or anesthesia [38].

The Doppler echocardiographic evaluation showed a maximal aortic velocity (AVmax) superior to the velocity of flow in the pulmonary artery (Pmax), also observed in animal models such as non-anesthetized agoutis [15], dogs [7], domestic pigs, minipigs [27], primates [43] and humans [3]. The evaluation of the transmitral flow, allowed the measurement of the $\mathrm{A}$ and $\mathrm{E}$ waves, which showed a positive and laminar flow, with the $\mathrm{E}$ wave peak higher than that of A wave. Studies using non-anesthetized agoutis reported difficulty in measuring these parameters due to the high sensitivity between the heart rate and the evaluation of the flows through Doppler [15]. In humans and non-sedated animals, HR can alter transmitral flow, exacerbating isovolumetric relaxation, reducing diastolic filling time and accelerating early left ventricular diastolic elastic recoil [21].

In the present study, although there was little variation in the HR, it had a negative correlation with the IVRT, which was lower in the animals in which HR was higher, despite the sedation state [22].

The pattern of E' and A' waves measured at the septal border of the mitral annulus was similar to those reported in dogs [35], animal models used in research (swine and rabbits) [27,41] and humans [33]. The animals studied presented TDI values similar to healthy humans, with no evidence of contractility deficits [40]. Once the LA/AO ratio was observed within the normality patterns described for other rodents and experimental animal models $[8,9,27,41]$, besides diastolic filling velocities ( $\mathrm{E}$ wave velocity, A wave velocity and E/A relationship) within the limits of normality [33], diastolic function is presumed to be preserved in the animals studied.

The velocity obtained by the radial strain for the apical systolic peak $(42.16 \pm 4.31 \%)$ was slightly lower than that obtained for the basal systolic peak $(43.12 \pm 4.75 \%)$, while the opposite was observed for the circumferential strain, which demonstrated apical peak $(-21.36 \pm 3.74 \%)$ greater than the basal peak $(-16.17 \pm 4.68 \%)$, similarly to that found for humans [12]. The values obtained for circumferential, radial and longitudinal strains for agoutis were within normal ranges for healthy humans [13].
In the present study, all radial strain curves were positive in systole, whereas the longitudinal and circumferential strains had negative values. Similarly, these findings have been described in humans with preserved cardiac function [1]. The radial strain during systole is positive, since it reflects the myocardial thickening, the final length being greater than the initial one. On the other hand, the longitudinal and circumferential strains are negative, since the initial length is larger than the final [36].

The cardiac twist obtained for the agoutis showed to be qualitatively similar to that of humans. In humans this torsion angle allows comparisons between hearts of different sizes. Research papers compared the heart twist of humans and mice, which differed only in magnitude. However, despite the discrepant size between hearts, the torsion was quantitatively comparable in these two species [23].

The bull eyes generated from the performed analyzes presented a homogeneous pattern, with no evidence of contractility deficits in the 18 segments generated. The rate of cardiac deformation was similar to that obtained in the human species, despite the sedation performed [38].

Few studies on indices of myocardial deformation in animals have been reported, and none specifically with a group of wild rodents. Despite the relatively small amount of animals, this study suggests that myocardial strain, strain and strain rate indices are an applicable technique in clinical investigations with agoutis.

\section{CONCLUSION}

The present study allowed the presumed normal values of the chambers and cardiac walls dimensions, strain and strain rate by two-dimensional speckle tracking of agoutis, chemically contained with ketamine and xylazine. The similarities observed with the human species for cardiac function values obtained by strain by Speckle tracking technique in agoutis suggest that these animals have the potential to be exploited as animal models in preclinical studies in cardiology.

\section{MANUFACTURERS}

${ }^{1}$ Mercur®. São Paulo, SP, Brazil.

${ }^{2}$ Fujifilm SonoSite Inc. Bothell, WA, USA.

${ }^{3}$ Philips Medical Systems. São Paulo, SP, Brazil. 
Acknowledgments. The authors thank the Diagnosis by Image Sector of the University Veterinary Hospital, UFPI, for making the animals available. They also thank the Coordination for the Improvement of Higher Education Personnel (CAPES), for the master degree grant.

Ethical approval. The protocols used in this study were approved by the Committee on Ethics in Animal Experimentation - EAA / UFPI ( $\left.N^{\circ} 0117 / 2015\right)$, and authorized by the Ministry of the Environment, through the System of Authorization and Information of Biodiversity - SISBIO of the Brazilian Institute of the Environment and Natural Renewable Resources - IBAMA (No 26101-1).

Declaration of interest. The authors report no conflicts of interest. The authors alone are responsible for the content and writing of paper.

\section{REFERENCES}

1 Abduch M.C.D., Alencar A.M., Mathias Jr. W. \& Vieira M.L.C. 2014. Cardiac Mechanics Evaluated by Speckle Tracking Echocardiography. Arquivo Brasileiro de Cardiologia. 1(1): 1-10.

2 Allen D.G. 1982. Echocardiographic study of the anaesthetized cat. Canadian Journal of Comparative Medicine. 46: 115-122.

3 Ângelo L.C.S., Vieira M.L.C., Rodrigues S.L., Morelato R.L., Pereira A.C., Mill J.G. \& Krieger J.E. 2007. Echocardiographic Reference Values in a Sample of Asymptomatic Adult Brazilian Population. Arquivo Brasileiro de Cardiologia. 89(3): 168-173.

4 Batista J.S., Bezerra F.S.B., Lira R.A., Orpinelli S.R.T., Dias C.E.V. \& Oliveira A.F. 2008. Síndrome do stress em catetos (Tayassu tajacu) submetidos à captura e contenção em diferentes horários da manhã em Mossoró, RN. Ciência Animal Brasileira. 9: 170-176.

5 Bham A., Sirke A., Zhang J., Protti A., Catibog N., Driver W., Botnar R., Monaghan M.J. \& Shah A.M. 2014. High-frequency speckle tracking echocardiography in the assessment of left ventricular function and remodeling after murine myocardial infarction. American Journal of Physiology-Heart and Circulatory Physiology. 306(9): 1371-1383.

6 Black P.A., Marshall C., Alice W., Seyfried B.S. \& Bartin A.M. 2011. Cardiac Assessment of African Hedgehogs (Atelerix albiventris). Journal of Zoo and Wildlife Medicine. 42(1): 49-53.

7 Boon J. 2011. Evaluation of size, function and hemodynamics. In: Boon J. (Ed). Veterinary echocardiography. Chichester: John Wiley \& Sons, pp.153-267.

8 Botelho A.F.M., Oliveira M.S., Blanco B.S. \& Melo M.M. 2016. Computerized electrocardiography in healthy conscious guinea pigs (Cavia porcellus). Pesquisa Veterinária Brasileira. 36(12): 1203-1208.

9 Bradley L.M. \& Ross J.N. 1987. M-mode echocardiographic values in sheep. American Journal of Veterinary Research. 48: 1313-1318.

10 Cetin N., Cetin E. \& Toker M. 2005. Echocardiographic variables in healthy guineapigs anaesthetized with ketaminexylazine. Laboratory Animals. 39(1): 100-106.

11 Chetboul V., Serres F., Gouni V., Tissier F. \& Pouchelon J.L. 2007. Radialstrain and strain rate by two-dimensional speckle tracking echocardiography and tissue velocity based technique in the dog. Journal of Veterinary Cardiology. 9: 69-81.

12 D'hooge J., Heimdal A., Jamal F., Kukulski T., Bijnens B., Rademakers F., Hatle L., Suetens P. \& Sutherland G.R. 2000. Regional strain and strain rate measurements by cardiac ultrasound: principles, implementation and limitations. European Journal of Echocardiography. 1: 154-170.

13 Dalen H., Thorstensen A., Aase S.A., Ingul C.B., Torp H., Vatten L.J. \& Stoylen A. 2010. Segmental and global longitudinal strain and strain rate based on echocardiography of 1266 healthy individuals: the HUNT study in Norway. European Journal of Echocardiografia. 11: 176-183.

14 Diniz A.N., Silva Júnior J.R., Guerra P.C., Barreto-Júnior R.A., Almeida H.M., Freire L.D., Ambrósio C.E. \& Alves F.R. 2013. Electrocardiogram. Assessment in non-anaesthetized clinically healthy agouti (Dasyprocta primnolopha, Wagler 1831). Pesquisa Veterinária Brasileira. 33: 8-14.

15 Diniz A.N., Pessoa G.T., Moura L.S., Sousa F.C.A., Rodrigues R.P.S., Souza A.B., Almeida H.M., Freire L.D.S., Sanches M.P. \& Alves F.R. 2017. Echocardiographic findings in bidimensional mode, M-mode and Doppler of clinically normal black - rumped agouti (Dasyprocta prymnolopha, Wagler 1831). Journal of Zoo and Wildlife Medicine. 48(2): 287-293. 
16 Elagha A. \& Fuisz A. 2012. Validade mitral E-point to separation Septal (EPSS) medição po ressonância magnética cardíaca Mitral valve E-Point to Septal Separation (EPSS) measurement by cardiac magnetic resonance Imaging as a quantitative surrogate of Left Ventricular Ejection Fraction (LVEF). Journal of Cardiovascular Magnetic Resonance. 14: 1-3.

17 Enriquez-Sarano M. \& Tajik A.J. 2004. Clinical practice. Aortic regurgitation. The New England Journal of Medicine. 351(15): 1539-1546

18 Fantoni D.T. Cortopassi S.R.G. \& Bernardi M.M. 2006. Anestésicos intravenosos e outros parenterais. In: Farmacologia Aplicada à Medicina Veterinária. São Paulo: Guanabara Koogan, pp.132-143.

19 Fortes E.A.M., Ferraz M.S., Bezerra D.O., Conde-Júnior A.M., Cabral R.M., Sousa F.C.A., Almeida H.M., Pessoa G.T., Menezes D.J.A., Guerra S.P.L., Sampaio I.B.M., Assis-Neto A.C. \& Carvalho M.A.M. 2013. Prenatal development of the agouti (Dasyprocta prymnolopha, Wagler, 1831): External features and growth curves. Animal Reproduction Science. 140(3): 195-205.

20 Garcia E.B., Eshar D., Thomason J.D., Harkin K.R. \& Biller D. 2016. Cardiac assessment of zoo-kept, blacktailed prairie dogs (Cynomys ludovicianus) anesthetized with isoflurane. Journal of Zoo and Wildlife Medicine. 47(4): 955962.

21 Graziosi P. 1998. Análise ecocardiográfica da função diastólica do ventrículo esquerdo na hipertensão arterial. Hiper Ativo. 5(2): 175-188.

22 Harrison M.R., Clifton E.D., Pennel A. \& De Maria A.N. 1991. Effect of heart rate on left ventricular diastolic transmitral flow velocity patterns assessed by Doppler echocardiography in normal subjects. American Journal of Cardiology. 67(7): 622-627.

23 Henson R.E., Song S.K., Pastorek J.S., Ackerman J.J. \& Lorenz C.H. 2000. Left ventricular torsion is equal in mice and humans. Journal of Physiology: Heart and Circulation Physiology Physiol. 278(4): 1117-1123.

24 Kienle R.D. \& Thomas W.P. 2005. Ecocardiografia. In: Nyland T.G. \& Mattoon J.S. (Eds). Ultrassom diagnóstico em pequenos animais. 2.ed. São Paulo: Roca, pp.365-438.

25 Koch J., Pedersen H.D., Jensen A.L. \& Flagstad A. 1996. M-mode echocardiography diagnosis of dilated cardiomyopathy in giant breed dogs. Journal of Veterinary Medicine. 43: 297-304.

26 Laguens R. \& Crottogini A. 2009. Cardiac regeneration: the gene therapy approach. Expert Opinion on Biological Therapy. 9: 411-425.

27 Lee M.Y., Lee S.H., Lee S.G., Park S.H., Lee C.Y., Kim K.H., Hwang S.H., Lim S.Y., Ahn Y.K. \& Han H.J. 2007. Comparative analysis of heart functions in micropigs and conventional pigs using echocardiography and radiography. Journal of Veterinary Science. 8(1): 7-14.

28 Lin H.C., Thurmon J.C., Benson G.J. \& Tranquilli W.J. 1993. Telazol: A review of its pharmacology and use in veterinary medicine. Journal of Veterinary Pharmacology and Therapeutics. 16: 383-418.

29 Locatelli O., Olea F.D., De Lorenzi A., Salmo F. Janavel G.L.V., Hnatiuk A.P., Guevara E. \& Crottogini A.J. 2011. Reference values for echocardiographic parameters and indexes of left ventricular function in healthy, young adult sheep used in translational research: comparison with standardized values in humans. Internal Journal of Clinical Experimental Medicine. 4(4): 258-264.

30 Muir W.W. \& Gaynor J.S. 2015. Handbook of veterinary pain management. St. Louis: Mosby, 641p.

31 Moura C.R.C., Diniz A.N., Moura L.S., Sousa F.C.A., Baltazar P.I., Freire L.D., Guerra P.C., Sousa J.M., Giglio R.F., Pessoa G.T., Rodrigues R.P.S. \& Alves F.R. 2015. Cardiothoracic Ratio and Vertebral Heart Scale in Clinically Normal Black-Rumped Agoutis (Dasyprocta prymnolopha, Wagler 1831). Journal of Zoo and Wildlife Medicine. 46(2): 314-319.

32 Nishimura R.A. \& Housmans P.R. 1989. Assessment of diastolic function of the heart: baxkground and current applications of Doppler echocardiography. Part I. Physiologic and Pathophysiologic Features. Mayo Clinic Proceeding. 64: 71- 81.

33 Parro Jr. A., Cherubini M.L.C., Miola L., De Matos C. \& Manzano E. 2003. Doppler Tecidual na Caracterização do Fluxo de Enchimento Ventricular Esquerdo de Aspecto Normal. Revista Brasileira de Ecocardiografia. 3: 42-52.

34 Pellegrino A., Petrus L.C., Pereira G.G., Soares E.C., Yamato R.J. Fernandez E.L. \& Larsson M.H.M.A. 2007. Padronização de parâmetros ecocardiográficos de cães da raça Golden Retriever clinicamente sadios. Ciência Rural. 37(4): 1039-1044. 
35 Pellegrino A.E., Daniel A.G.T., Pereira G.G., Lima Júnior F.F., Itikawa P.H. \& Larsson M.H.M.A. 2014. Avaliação da função diastólica por meio de Doppler tecidual pulsado e colorido em gatos da raça Maine Coon geneticamente testados para a mutação no gene MyBPC-A31P1. Pesquisa Veterinária Brasileira. 34(3): 290-300.

36 Pena J.L.B., Silva M.G., Faria S.C.C., Alves Jr. J.M.S., Salemi V.M.C., Mady C. \& Sutherland G.R. 2012. Índices Regionais de Deformação Miocárdica (Strain/Strain Rate) em Neonatos Normais Regional Deformation Indices (Strain/ Strain Rate). Revista Brasileira de Ecocardiografia. 25(4): 267-277.

37 Philip R.F., Bond B.R. \& Peterson M.E. 1985. Echocardiographic values in healthy cats sedated with ketamine hydrochloride. American Journal of Veterinary Research. 46: 1479-1484.

38 Roth D.M., Swaney J.S., Dalton N.D., Gilpin E.A. \& Ross J.R.J. 2002. Impact of anesthesia on cardiac function during echocardiography in mice. American Journal of Physiology: Heart and Circulation Physiology. 282: 2134-2140.

39 Schmidt-Nielsen K. 1999. Fisiologia animal: adaptações e meio ambiente. 5.ed. São Paulo: Santos Livraria, 600p.

40 Shojaefard M., Esmaeilzadeh M., Maleki M., Bakhshandeh H., Parvaresh F. \& Naderi N. 2013. Normal Reference Values of Tissue Doppler Imaging Parameters for Right Ventricular Function in Young Adults: a Population Based Study. Reseach in Cardiovascular Medicine. 2(4): 160-166.

41 Silva E.F., Borboleta L.R., Telles T.C., Fonseca V.B. \& Melo M.M. 2011. EcoDopplercardiografia em coelhos: uso de midazolam e midazolam associado à cetamina. Arquivo Brasileiro de Medicina Veterinária e Zootecnia. 63(6): 1399-1404.

42 Silva-Filho O.F., Pessoa G.T., Rodrigues R.P.S., Silva A.B.S., Moura L.S., Sousa F.C. A., Barbosa M.A.P.S., Alves J.J.R.P., Macedo K.V. \& Alves F.R. 2017. Electrocardiographic Pattern of Agoutis (Dasyprocta prymnolopha) Chemically Contained by the Association of Ketamine and Xylazine. Acta Scientiae Veterinariae. 45: 1-9.

43 Sleeper M.M., Gaughan J.M., Gleason C.R. \& Burkett D.E. 2008. Echocardiographic Reference Ranges for Sedated Healthy Cynomolgus Monkeys (Macaca fascicularis). Journal of the American Association for Laboratory Animal Science. 47(1): 22-25.

44 Sousa M.G. 2015. Sistema Cardiovascular. In: Feliciano M.A.R., Canola J.C. \& Vicente W.R.R. (Eds). Diagnóstico por imagem em cães e gatos. 4.ed. São Paulo: MedVet, pp.669-682.

45 Stypmann J., Engelen M.A., Breithardt A. Milberg P., Rothenburger M., Breithardt O.A., Breithardt G., Eckardt L. \& Cordula P.N. 2007. Doppler echocardiography and tissue Doppler imaging in the healthy rabbit: differences of cardiac function during awake and anaesthetised examination. Internal Journal of Cardiology. 115: 164-170.

46 Suffoletto B., Merrill J.E., Chung T., Kristan J., Vanek M. \& Clark B. 2016. A text message program as a booster to in-person brief interventions for mandated college students to prevent weekend binge drinking. Journal of American College Health. 64(6): 481-489.

47 Tilley L.P. 1992. Essentials of canine and feline electrocardiography: Interpretation and treatment. Philadelphia: Lea \& Febiger, 470p.

48 Uscategui R.A.R., Almeida V.T., Kawanami A.E., Restan W.A.Z., Barros, F.F.P.C., Feliciano M.A.R., Machado M.R.F. \& Vicentte W.R.R. 2016. Electrocardiographic exam in female spotted pacas (Cuniculus paca). Pesquisa Veterinária Brasileira. 36(6): 559-563.

49 Vastenburg M.H., Boroffka S.A. \& Schoemaker N.J. 2004. Echocardiographic measurements in clinically healthy ferrets anesthetized with isoflurane. Veterinary Radiology and Ultrasound. 45(3): 228-232.

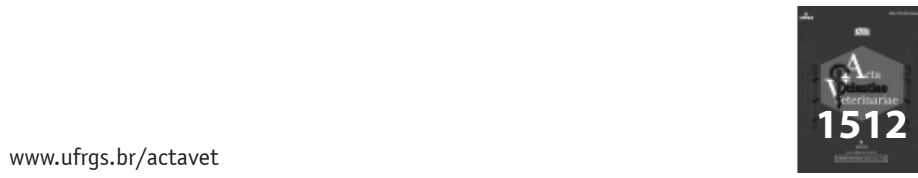

